\title{
A comparative impact evaluation of two human resource models for community- based active tuberculosis case finding in Ho Chi Minh City, Viet Nam
}

Luan Nguyen Quang Vo ${ }^{1,2^{*}}$ (D), Rachel Jeanette Forse ${ }^{1}$, Andrew James Codlin ${ }^{1}$, Thanh Nguyen Vu ${ }^{3}$, Giang Truong Le ${ }^{3}$, Giang Chau Do ${ }^{4}$, Vinh Van Truong ${ }^{4}$, Ha Minh Dang ${ }^{4}$, Lan Huu Nguyen ${ }^{4}$, Hoa Binh Nguyen ${ }^{5}$, Nhung Viet Nguyen ${ }^{5}$, Jens Levy ${ }^{6}$, Bertie Squire ${ }^{7}$, Knut Lonnroth ${ }^{8}$ and Maxine Caws ${ }^{7,9}$

\begin{abstract}
Background: To achieve the WHO End TB Strategy targets, it is necessary to detect and treat more people with active TB early. Scale-up of active case finding (ACF) may be one strategy to achieve that goal. Given human resource constraints in the health systems of most high TB burden countries, volunteer community health workers (CHW) have been widely used to economically scale up TB ACF. However, more evidence is needed on the most cost-effective compensation models for these CHWs and their potential impact on case finding to inform optimal scale-up policies.
\end{abstract}

Methods: We conducted a two-year, controlled intervention study in 12 districts of Ho Chi Minh City, Viet Nam. We engaged CHWs as salaried employees (3 districts) or incentivized volunteers (3 districts) to conduct ACF among contacts of people with TB and urban priority groups. Eligible persons were asked to attend health services for radiographic screening and rapid molecular diagnosis or smear microscopy. Individuals diagnosed with TB were linked to appropriate care. Six districts providing routine NTP care served as control area. We evaluated additional cases notified and conducted comparative interrupted time series (ITS) analyses to assess the impact of ACF by human resource model on TB case notifications.

Results: We verbally screened 321,020 persons in the community, of whom 70,439 were eligible for testing and 1138 of them started TB treatment. ACF activities resulted in a $+15.9 \%[95 \% \mathrm{Cl}:+15.0 \%,+16.7 \%]$ rise in All Forms TB notifications in the intervention areas compared to control areas. The ITS analyses detected significant positive post-intervention trend differences in All Forms TB notification rates between the intervention and control areas $(p=0.001)$, as well as between the employee and volunteer human resource models $(p=0.021)$.

(Continued on next page)

\footnotetext{
* Correspondence: luan.vo@tbhelp.org

${ }^{1}$ Friends for International TB Relief, 68B Nguyen Van Troi, 8, Phu Nhuan, Ho Chi Minh City, Viet Nam

${ }^{2}$ Interactive Research and Development, Ho Chi Minh City, Viet Nam

Full list of author information is available at the end of the article
}

(c) The Author(s). 2020 Open Access This article is licensed under a Creative Commons Attribution 4.0 International License, which permits use, sharing, adaptation, distribution and reproduction in any medium or format, as long as you give appropriate credit to the original author(s) and the source, provide a link to the Creative Commons licence, and indicate if changes were made. The images or other third party material in this article are included in the article's Creative Commons licence, unless indicated otherwise in a credit line to the material. If material is not included in the article's Creative Commons licence and your intended use is not permitted by statutory regulation or exceeds the permitted use, you will need to obtain permission directly from the copyright holder. To view a copy of this licence, visit http://creativecommons.org/licenses/by/4.0/ The Creative Commons Public Domain Dedication waiver (http://creativecommons.org/publicdomain/zero/1.0/) applies to the data made available in this article, unless otherwise stated in a credit line to the data. 
(Continued from previous page)

Conclusions: Both salaried and volunteer CHW human resource models demonstrated additionality in case notifications compared to routine case finding by the government TB program. The salaried employee CHW model achieved a greater impact on notifications and should be prioritized for scale-up, given sufficient resources.

Keywords: Comparative impact evaluation, Human resource model, Employees, Volunteers, Community health workers, Tuberculosis, Active case finding, Viet Nam

\section{Background}

Globally, 1.6 million people die of tuberculosis (TB) annually and an estimated 10 million people develop TB disease each year [1]. Despite concerted efforts, incidence is currently declining at less than $2 \%$ per annum [2]. If this trend continues, TB elimination will not be achieved until the year 2182 [3]. As for all infectious diseases, early detection and cure of incident cases is crucial to decrease transmission and halt the epidemic. In endemic countries, National TB Control Programs (NTP) are responsible for providing TB care and prevention to the population. However, in routine NTP operations case finding entails receiving health-seeking patients with little effort on actively searching for new TB cases. As a consequence, there are 3 million annual incident TB cases globally whom these NTPs fail to reach. This "detection gap" sustains transmission and mortality [4]. One strategy to close the detection gap is active case finding (ACF) [5]. This has led to a global surge in ACF initiatives beyond routine household contact tracing [6, 7]. These initiatives range from facility-based systematic screening to community-based interventions among vulnerable populations $[8,9]$. These initiatives have also shown that ACF can find more people with TB at an earlier stage of disease progression [10,11]. However, better evidence on impact and cost-effectiveness is needed if they are to be sustained through national public health policies and budgets [12].

A prerequisite for ending TB entails the optimal engagement of communities. Community engagement has long been recognized as a priority in health care $[13,14]$ and the fight against TB $[15,16]$. Previously defined as "paraprofessionals or lay individuals with an in-depth understanding of the community culture and language" that "have received standardized job-related training of a shorter duration than health professionals" with the primary goal of providing "culturally appropriate health services to the community," [17] community health workers (CHW) comprise a critical component of community engagement [18]. When effectively engaged, CHWs can raise health system capacity through decentralization and task-shifting $[19,20]$. CHW's often also reduce access barriers for vulnerable populations, so that their services are considered more patient-centric than institutionally provided care [21]. As such, CHW's comprise an ideal group to implement ACF for TB in their communities. However, there remains substantial heterogeneity in the CHW models applied and gaps in understanding regarding their optimal means of engagement $[17,22]$.

Under most applied models, CHW receive either a salary or an incentive-driven compensation. Oftentimes performance-based incentives (PBI) are additionally offered to reward high performers [23]. While salaried CHWs have been associated with increased motivation and reduced attrition [23], volunteer CHW models are often more attractive to authorities and implementers due to their lower fixed costs. Irrespective of payment model, a consistent recommendation is that financial compensation should be commensurate with occupational demands [18]. It has further been noted that CHWs are generally poor and dependent on the remuneration for their livelihood. For this reason, the World Health Organization (WHO) recommends to limit the dominance of PBIs as part of the overall compensation package [24]. However, it remains unclear whether a higher fixed payment is associated with improved performance and greater impact. The comparative effectiveness between salaried and volunteer CHWs was therefore identified as a key knowledge gap in need of further studies [25].

Between 2014 and 2016, a community-based ACF project named PROPER CARE was piloted in Go Vap district, Ho Chi Minh City (HCMC), Viet Nam. This project employed CHWs on a full-time basis with a commensurate salary for ACF and case management. Despite positive results [26], aspirations of other district health authorities to scale up this ACF initiative were stifled by the resource demands of these salaried CHWs. In response, we devised the IMPACT-TB study (Implementing proven community-based active TB case finding interventions). Its aim was to scale up the ACF activities piloted under the PROPER CARE project, to measure changes in TB case notifications resulting from these ACF activities, and to compare the relative changes in $\mathrm{TB}$ case notifications between ACF implemented by incentivized volunteers and salaried employees.

\section{Methods}

Study setting

The IMPACT-TB study was conducted in 12 of the 24 districts of HCMC (Fig. 1) between October 2017 and 


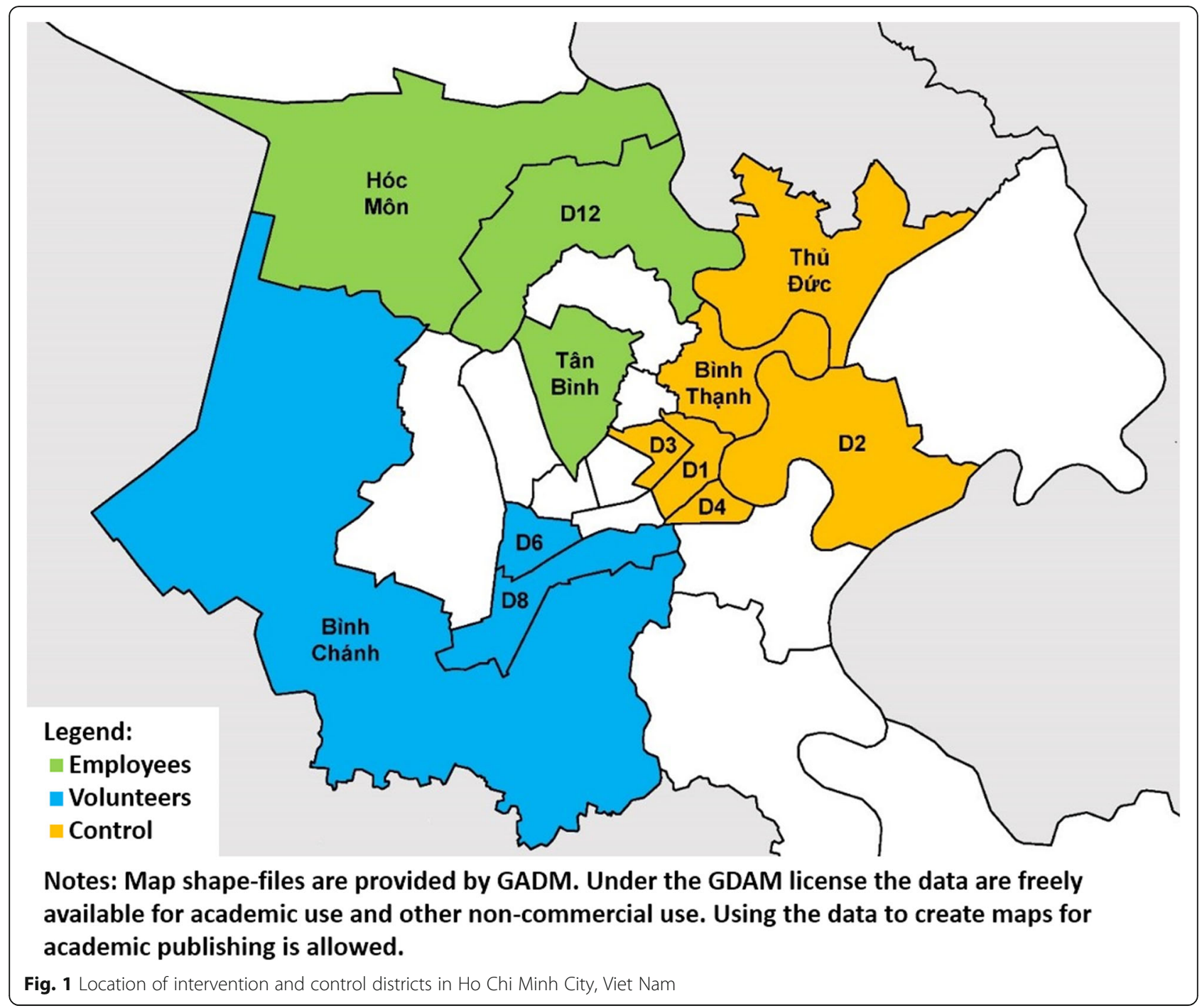

September 2019. Six intervention districts implemented ACF activities bifurcated by human resource model. In six control districts, routine TB care was provided by the NTP. The intervention districts were selected based on comparability of population size and TB burden, and absence of past or concurrent ACF activities. The human resource model was allocated in collaboration with the Pham Ngoc Thach Provincial TB Hospital (PNTH). The salaried employee model was implemented in Hoc Mon, Tan Binh and District 12. This area had a population of 1,465,819 and reported 1969 All Forms TB notifications in 2017. The volunteer model was implemented in Districts 6, 8 and Binh Chanh. This area had a population of $1,348,215$ and reported 2190 All Forms TB notifications in 2017. The six control districts had a combined population of 1,789,396 and reported 2859 All Forms TB notifications in 2017. Each of the 12 project districts contained one District TB Unit (DTU) which received regular technical supervision from PNTH. The DTUs managed TB diagnosis, notification and treatment follow up in accordance with national guidelines.

\section{Community health workers}

A cadre of CHWs was recruited in each intervention district to implement ACF activities. These individuals were identified by district authorities among current community volunteers, retired health staff, civil society members, and former TB patients. Residency in the district for over 5 years was a prerequisite to ensure geographic familiarity. CHWs were recruited by the district health authorities for the duration of the study as salaried employees or incentivized volunteers based on the study district. In our study, salaried employees were defined as full-time staff for the duration of the study, who focused solely on the ACF activities and TB patient support. These employees received a salary equivalent to USD 136/month. Volunteers 
had permission to engage in other livelihood generation activities. They were provided a stipend of USD 23/month to support study objectives. Both groups received the same training, core responsibilities and PBI schemes.

\section{Intervention}

CHWs targeted household and close contacts of index cases, neighbors in proximity of an index case, and urban priority groups living in slum and boarding home settings (Supplemental Information, Figure S1). Index cases were prospective TB patients notified by the DTUs of the intervention districts. Household contacts were defined as people sharing a kitchen with an index case for one or more nights in the past 3 months. Close contacts were persons that interacted with an index patient at least once per month over the past 3 months. Proximity was defined as the same administrative neighborhood or in a $50 \mathrm{~m}$ catchment area around the residence of the index case [27]. We used United Nations Habitat definitions for slum households [28]. Boarding homes were defined as dormitories and single-room rental facilities. District authorities further helped to identify boarding home and urban poor communities for door-to-door screening.

Household contact investigations consisted of an enumeration of all contacts and verbal symptom screening of those who were present at the time of the contact investigation. Screening of close contacts was conducted either via phone or pre-arranged meeting. To screen index case neighbors and urban priority groups, CHWs conducted door-to-door visits. A verbal symptom screen was administered using a standardized questionnaire in a custom-built app installed on an Android tablet (Supplemental information, Data sources \& processing). The questionnaire asked about the presence and duration of the following symptoms: cough, hemoptysis, chest pain, dyspnea, fever, night sweats, fatigue, weight loss, and history of TB.

Although all household contacts were first verbally screened for TB symptoms, they were all referred for additional chest X-ray (CXR) screening irrespective of their clinical presentation. All other persons were referred for CXR screening if they reported any one of the aforementioned symptoms. Persons with parenchymal abnormalities on CXR were tested on the Xpert MTB/ RIF assay (Cepheid; Sunnyvale, CA, USA). Individuals who did not obtain a CXR or had a normal CXR but exhibited TB-related symptoms were tested using smear microscopy. Symptomatic persons with negative sputum test results were evaluated by the DTU and PNTH for clinical diagnosis in accordance to national treatment guidelines.

Persons accessing care received a transport stipend and fully subsidized CXR at the DTU or weekend community screening events. CHWs transported sputum samples for persons unable to reach the laboratories. TB patients with rifampicin-susceptible TB were linked to treatment at the DTU. This included CHWs assisting with enrollment formalities, including support to furnish proof of residency. Rifampicin-resistant TB patients were referred to PNTH for further evaluation and treatment. CHWs followed up patients before and after enrollment for counseling and psychosocial support.

\section{Study population}

The study population included all household contacts, as well as close contacts and urban priority groups with clinical symptoms for whom CHWs completed a verbal symptom screen. Screened persons that declined to participate were referred, but their information was excluded from the analysis.

\section{Study outcomes}

The primary outcome was the additionality in All Forms TB notifications in the intervention area. The secondary outcome was the difference in All Forms TB additionality between the two human resource models. We calculated additionality using the double-difference approach [29]. This approach calculates the additive effect of the pre-/post intervention difference in case notifications, plus the concurrent notification trend difference in a control area.

\section{Statistical analyses}

We described the TB care cascade [30] bifurcated by human resource model. We presented the doubledifference additionality for All Forms TB notifications and for TB patients with bacteriologic confirmation. To assess the validity of the double-difference additionality, we conducted comparative interrupted time series (ITS) analyses of aggregate monthly TB case notification rates in two iterations. The first iteration compared the intervention and control areas. The second iteration compared the two human resource models. The ITS analyses employed segmented methods (Supplemental Information, Figure S2) applied to marginal log-linear Poisson regression models using the generalized estimating equation (GEE) approach. We tested for serial autocorrelation using the CumbyHuizinga test with a cutoff of $p<0.1$ and specified the model based on the lowest quasi-likelihood information criterion values. Statistical analyses were performed on Stata version 13 (StataCorp; College Station, TX, USA). As a large proportion of the double-difference additionality derived from a decline in notifications the control area, we conducted a post-hoc comparative ITS analysis between the study's six control districts and eight non-study districts where no ACF had been conducted in the past 3 years (from a total of 12 non-study districts in HCMC). Hypothesis tests were two-sided and point estimates included 95\% confidence intervals. 


\section{Ethical considerations}

Ethical approvals were granted by the Pham Ngoc Thach Hospital Institutional Review Board and the Liverpool School of Tropical Medicine Research Ethics Committee. Study implementation was approved by the Ho Chi Minh City People's Committee. We obtained written informed consent from all participants and anonymized all patient data prior to analysis.

\section{Results}

\section{ACF outputs}

The TB care cascade is shown in Table 1 and Fig. 2 . Over 2 years, CHWs verbally screened 321,020 people. Of those, 70,439 (21.9\%) individuals were a household contact of a TB patient or had symptoms suggestive of $\mathrm{TB}$ and thus were eligible for further screening. A description of these individuals is in Table S1 of the supplemental information. We recorded CXR results for $62.3 \%(43,910 / 70,439)$ of these participants, among whom $11.6 \%(5106 / 43,910)$ had abnormalities. Xpert was used as the initial diagnostic test in $69.9 \%$ of persons with X-ray abnormalities (3567/5106). The Xpert positivity rate was $14.3 \%(511 / 3567) .14,781$ people with no CXR result or a normal CXR were tested on smear microscopy with a positivity rate of 5.0\% $(733 / 14,781)$. Active TB was diagnosed in $0.4 \%(1306 / 321,020)$ of persons screened, of whom $87.1 \%(1138 / 1306)$ started NTP treatment. This represented a Number Needed to Screen (NNS) of 282 or a yield of 354 per 100,000.
While most indicators along the TB care cascade were similar between the human resource models, there were some notable differences. The number of individuals verbally screened by salaried employees $(220,995)$ was $121 \%$ higher compared to volunteers $(100,025)$. Conversely, the number of patients started on TB treatment in the salaried employee districts (510) was 19\% lower than those started on treatment in the volunteer districts (628). As such, the NNS in for salaried employee districts (433) was 2.7 times higher than for volunteer districts (159).

\section{Notification impact}

Changes in TB notifications for primary and secondary outcomes are shown in Table 2. The cumulative additionality in All Forms TB notifications in all intervention districts was $+15.9 \%[+15.0 \%$, $+16.7 \%]$, corresponding to 1090 [1031, 1149] additional cases notified over 2 years. Pre-/post-implementation notification trend differences were $+5.0 \%[+4.5 \%,+5.5 \%]$ in the intervention compared to $-10.9 \%[-11.6 \%,-10.1 \%]$ in the control districts. Bacteriologically-confirmed TB notifications rose $+22.0 \%$ [+20.8\%, $+23.2 \%]$ corresponding to 1074 [1017, 1131] additional cases. Between pre- and postimplementation periods, notifications increased $+14.5 \%$ $[+13.5 \%,+15.4 \%]$ in the intervention area compared to a decline of $-7.5 \%[-8.3 \%,-6.7 \%]$ in the control.

The additionality in All Forms TB notifications disaggregated by human resource model was $+8.8 \%[+8.0 \%$,

Table 1 Process indicators disaggregated by human resource model

\begin{tabular}{|c|c|c|c|}
\hline & $\begin{array}{l}\text { Total } \\
\text { N (\%) }\end{array}$ & $\begin{array}{l}\text { Volunteer ACF } \\
N(\%)\end{array}$ & $\begin{array}{l}\text { Employee ACF } \\
\mathrm{N}(\%)\end{array}$ \\
\hline Individuals verbally screened & $321,020(100.0)$ & $100,025(100.0)$ & $220,995(100.0)$ \\
\hline Individuals consenting \& recruited ${ }^{a}$ & $70,439(21.9)$ & $34,129(34.1)$ & $36,310(16.4)$ \\
\hline Individuals eligible for CXR & $59,781(18.6)$ & $29,438(29.4)$ & $30,343(13.7)$ \\
\hline Individuals screened by CXR & $43,910(13.7)$ & $20,602(20.6)$ & 23,308 (10.5) \\
\hline Individuals with abnormal CXR screen & $5106(1.6)$ & $2484(2.5)$ & $2622(1.2)$ \\
\hline Individuals tested for TB (any sputum test) & $18,351(5.7)$ & $9071(9.1)$ & $9280(4.2)$ \\
\hline Individuals tested for TB with Xpert & $3567(1.1)$ & $1992(2.0)$ & $1575(0.7)$ \\
\hline Individuals tested for TB with Smear & $14,781(4.6)$ & $7078(7.1)$ & $7703(3.5)$ \\
\hline Individuals tested for TB with Culture & $3(0.0)$ & $1(0.0)$ & $2(0.0)$ \\
\hline Individuals diagnosed with All Forms TB & $1306(0.4)$ & $724(0.7)$ & $582(0.3)$ \\
\hline Individuals diagnosed Xpert(+) & $511(0.2)$ & $269(0.3)$ & $242(0.1)$ \\
\hline Individuals diagnosed Smear(+) & $733(0.2)$ & $411(0.4)$ & $322(0.1)$ \\
\hline Individuals diagnosed Culture(+) & $3(<0.1)$ & $1(<0.1)$ & $2(<0.1)$ \\
\hline Individuals clinically diagnosed ${ }^{b}$ & $59(<0.1)$ & $43(<0.1)$ & $16(<0.1)$ \\
\hline All Forms TB patients started on treatment & $1138(0.4)$ & $628(0.6)$ & $510(0.2)$ \\
\hline NNS / Yield & $282(0.4)$ & $159(0.6)$ & $433(0.2)$ \\
\hline
\end{tabular}

${ }^{a}$ Comprised of household contacts and symptomatic persons from other target groups that consented to participate in the study;

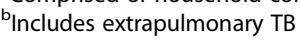




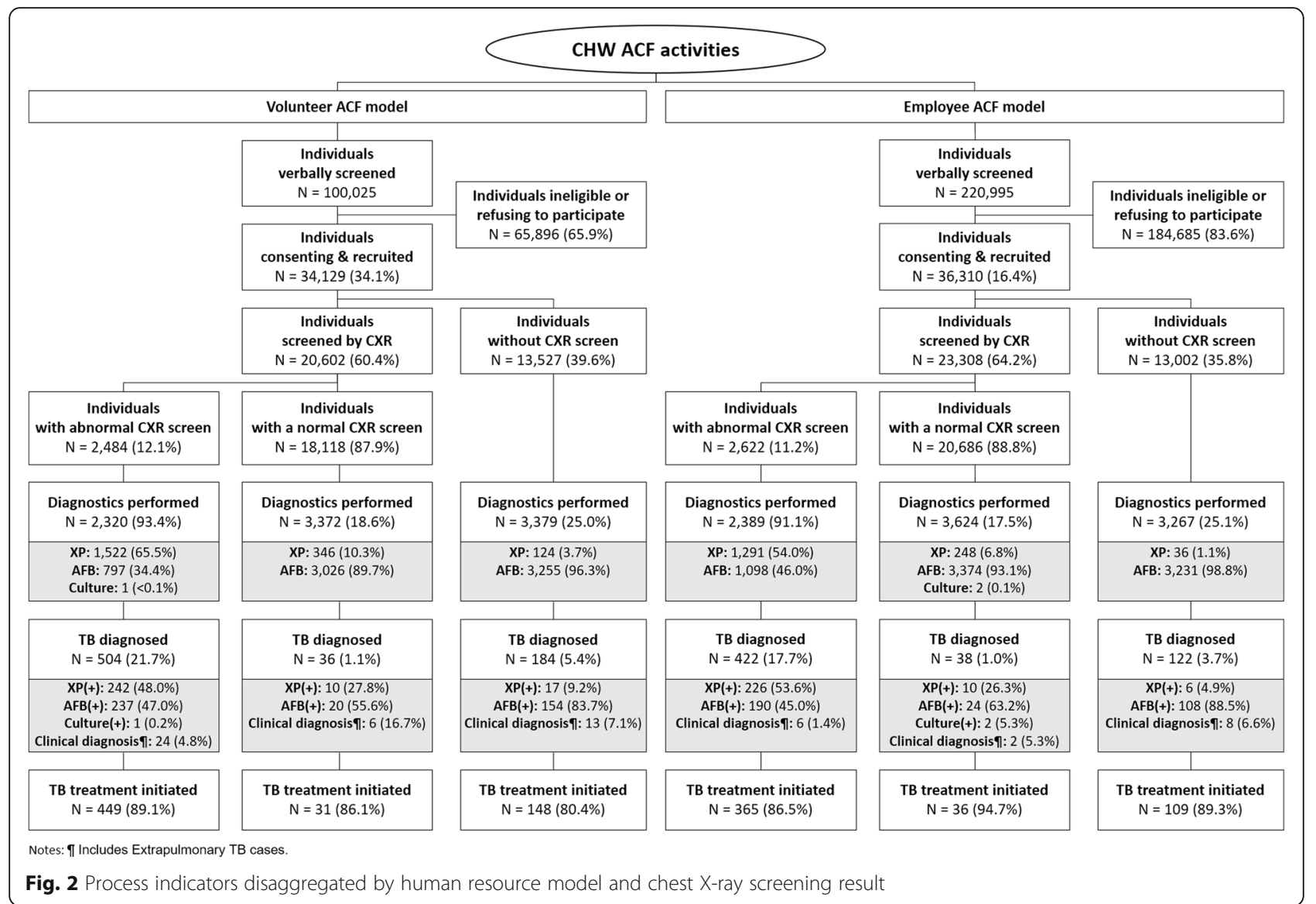

$+9.6 \%$ from volunteer districts compared to $+12.3 \%$ $[+11.4 \%,+13.2 \%]$ from salaried employee districts. These rates corresponded to $480[439,521]$ additional All Forms TB notifications in volunteer districts and 610 [565, 655] in salaried employee districts. With respect to bacteriologically-confirmed cases, volunteer districts raised notifications by an additional $+12.9 \%[+11.7 \%$, $+14.0 \%$ ] corresponding to 401 [364, 438] additional cases. The additionality in salaried employee districts was $+23.9 \%[+22.3 \%,+25.5 \%]$ corresponding to 673 $[629,717]$ additional cases.

\section{Secondary and post-hoc analyses}

The time series data consisted of 138 monthly aggregate counts of treatment notifications balanced between intervention and control districts. The monthly median All Forms TB notifications was 383 (Interquartile range: 358-403) in the intervention area and 249 (IQR: 233-265) in the control area. The ITS analyses results are in Table 3 and Fig. 3. In the postimplementation period, there was a significant trend difference between the intervention and control areas in All Forms TB (Incidence rate $\operatorname{ratio}\left(\beta_{7}\right)=1.004$ $[1.002,1.006] ; \quad p=0.001)$ and bacteriologically- confirmed TB notification rates $\left(\operatorname{IRR}\left(\beta_{7}\right)=1.008\right.$ $[1.003,1.014] ; p=0.002)$. Regarding the human resource models, the ITS analysis detected evidence of a post-intervention trend difference in favor of the salaried employee district over the volunteer districts in All Forms TB case notification rate $\left(\operatorname{IRR}\left(\beta_{7}\right)=1.005\right.$ [1.001, 1.009]; $p=0.021$ ).

The comparison between the study's control districts and eight selected non-study districts showed no statistical difference in step-change $\left(\beta_{6}\right)$ or trends $\left(\beta_{7}\right)$ for bacteriologically-confirmed and All Forms TB notifications (Table 4).

\section{Discussion}

Our study demonstrated that community-based ACF can generate a substantial yield of previously undetected $\mathrm{TB}$, even in a setting with a well-functioning TB program. Our ITS analyses substantiated the additionality calculations of the intervention by adjusting for changes in population size and seasonality. Although the trend differences in case notification rates were modest, they were statistically significant, supporting the case for a positive intervention impact. The post-hoc comparison 
Table 2 Additionality analysis [29] by study area and human resource model

\begin{tabular}{|c|c|c|c|c|c|c|}
\hline & \multicolumn{2}{|c|}{ Cumulative notifications } & \multicolumn{4}{|c|}{ Trend difference } \\
\hline & Baseline period $^{a}$ & $\overline{\text { Intervention period }}$ & \# cases & {$[95 \% \mathrm{Cl}]$} & $\%$ change $^{b}$ & {$[95 \% \mathrm{Cl}]$} \\
\hline \multicolumn{7}{|l|}{ All forms TB } \\
\hline Notification impact $^{\mathrm{d}}$ & & & 1090 & {$[1031,1149]$} & $15.9 \%$ & {$[15.0 \%, 16.7 \%]$} \\
\hline \multicolumn{7}{|l|}{ By study area } \\
\hline Intervention area & 8796 & 9236 & 440 & {$[400,480]$} & $5.0 \%$ & {$[4.5 \%, 5.5 \%]$} \\
\hline Control area & 5988 & 5338 & -650 & {$[-697,-603]$} & $-10.9 \%$ & {$[-11.6 \%,-10.1 \%]$} \\
\hline \multicolumn{7}{|l|}{ By human resource model } \\
\hline Volunteer ACF & & & 480 & {$[439,521]$} & $8.8 \%$ & {$[8.0 \%, 9.6 \%]$} \\
\hline Pre vs. post: Intervention & 4580 & 4722 & 142 & {$[119,165]$} & $3.1 \%$ & {$[2.6 \%, 3.6 \%]$} \\
\hline Pre vs. post: Control ${ }^{c}$ & 3118 & 2779 & -338 & {$[-376,-306]$} & $-5.7 \%$ & {$[-6.3 \%,-5.1 \%]$} \\
\hline Employee ACF & & & 610 & {$[565,655]$} & $12.3 \%$ & {$[11.4 \%, 13.2 \%]$} \\
\hline Pre vs. post: Intervention & 4216 & 4514 & 298 & {$[265,331]$} & $7.1 \%$ & {$[6.3 \%, 7.8 \%]$} \\
\hline Pre vs. post: Control ${ }^{\mathrm{C}}$ & 2870 & 2559 & -312 & {$[-345,-278]$} & $-5.2 \%$ & {$[-5.8 \%,-4.6 \%]$} \\
\hline \multicolumn{7}{|l|}{ Bacteriologically-confirmed TB } \\
\hline Notification impact $^{d}$ & & & 1074 & {$[1017,1131]$} & $22.0 \%$ & {$[20.8 \%, 23.2 \%]$} \\
\hline \multicolumn{7}{|l|}{ By study area } \\
\hline Intervention area & 5402 & 6183 & 781 & {$[730,832]$} & $14.5 \%$ & {$[13.5 \%, 15.4 \%]$} \\
\hline Control area & 3884 & 3591 & -293 & {$[-325,-261]$} & $-7.5 \%$ & {$[-8.4 \%,-6.7 \%]$} \\
\hline \multicolumn{7}{|l|}{ By human resource model } \\
\hline Volunteer ACF & & & 401 & {$[364,438]$} & $12.9 \%$ & {$[11.7 \%, 14.0 \%]$} \\
\hline Pre vs. post: Intervention & 2782 & 3032 & 250 & {$[220,280]$} & $9.0 \%$ & {$[7.9 \%, 10.0 \%]$} \\
\hline Pre vs. post: Control ${ }^{c}$ & 2000 & 1849 & -151 & {$[-175,-128]$} & $-3.9 \%$ & {$[-4.5 \%,-3.3 \%]$} \\
\hline Employee ACF & & & 673 & {$[629,717]$} & $23.9 \%$ & {$[22.3 \%, 25.5 \%]$} \\
\hline Pre vs. post: Intervention & 2620 & 3151 & 531 & {$[491,571]$} & $20.3 \%$ & {$[18.7 \%, 21.8 \%]$} \\
\hline Pre vs. post: Control ${ }^{c}$ & 1884 & 1742 & -142 & {$[-167,-121]$} & $-3.7 \%$ & {$[-4.3 \%,-3.1 \%]$} \\
\hline
\end{tabular}

between the study's control and selected non-study districts further substantiated this finding by showing that the notification declines recorded in the study's control areas were experienced across the majority of all nonstudy districts in HCMC.

Our results are concordant with those of communitybased ACF studies conducted in other settings [31-36]. A key success factor of these studies was expanding screening coverage to large portions of vulnerable populations and enabling access to the more sensitive CXR-Xpert diagnostic algorithm. Another commonality was leveraging existing healthcare structures. Successful community engagement projects tended to be complementary to facility-based case finding [37]. The engagement of established networks has been shown to be effective in other health areas as well [38]. A final similarity entailed the strong community linkages. Our CHWs coordinated with neighborhood leaders and commune TB officers to conduct household contact investigations. This raised community confidence in the study and lowered access barriers [39].

In evaluating the two human resource models, we found both to be successful in improving $\mathrm{TB}$ detection and notification. Our analysis further showed that these yields did not displace routine activities in either model. This suggests that there is a general benefit to engaging CHWs for community-based TB service coverage expansion. We further found that despite a lower case detection yield, the increases in All Forms TB notifications in the salaried employee districts was significantly higher than the gains in the 
Table 3 Comparative ITS analysis model parameters ${ }^{a}$ of population-standardized monthly notification rates of All Forms and bacteriologically-confirmed TB cases for a) intervention versus control districts; and b) employee ACF versus volunteer ACF

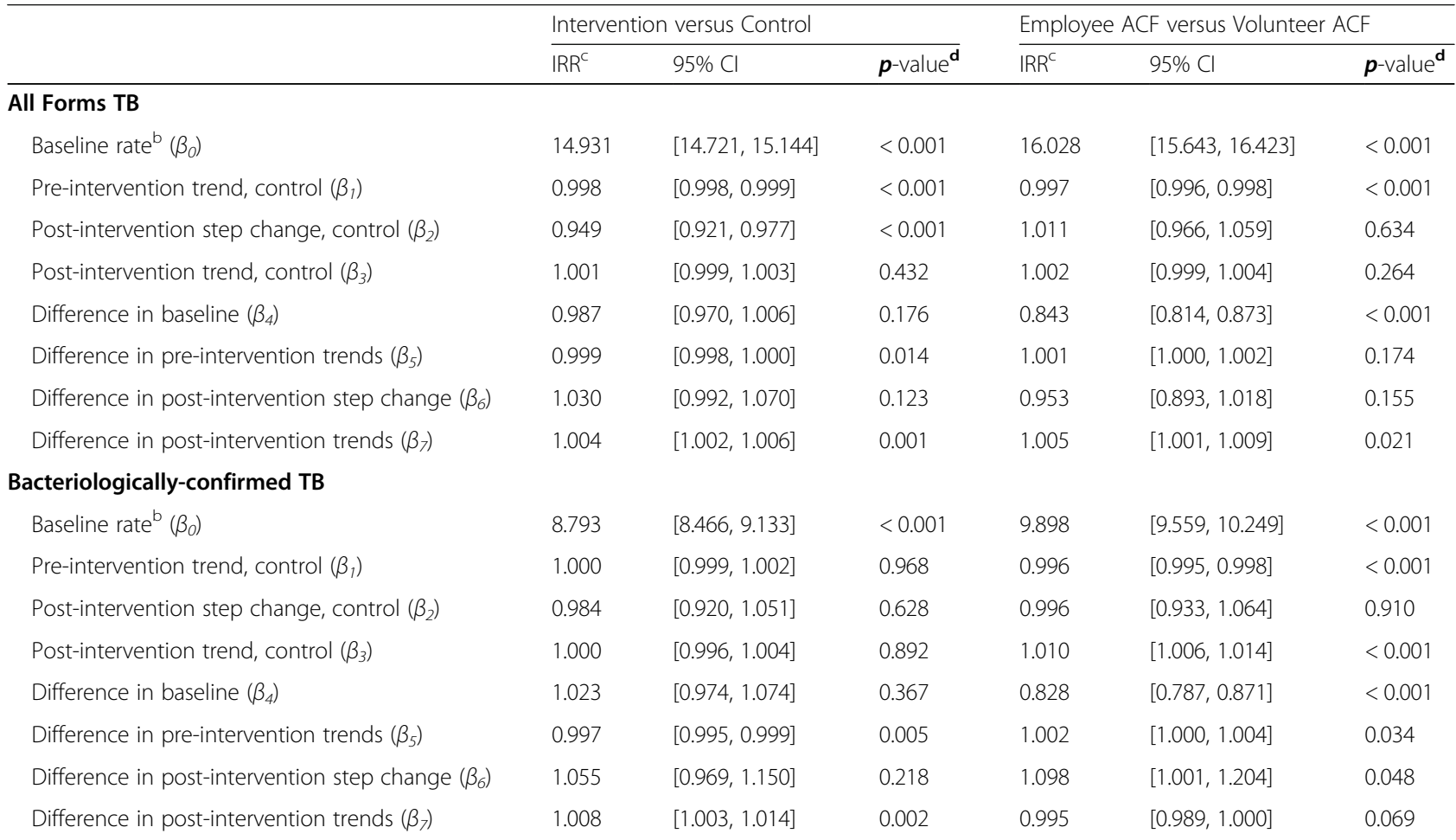

${ }^{a}$ The parameters were obtained for a segmented regression model with the following structure: $Y_{t}=\beta_{0}+\beta_{1} T_{t}+\beta_{2} X_{t}+\beta_{3} X_{t} T_{t}+\beta_{4} Z+\beta_{5} Z T_{t}+\beta_{6} Z X_{t}+\beta_{6} Z X_{t} T_{t}+\epsilon_{t}$. Here $Y_{t}$ is the outcome measure along time $t ; T_{t}$ is the monthly time counter; $X_{t}$ indicates pre- and post-intervention periods, $Z$ denotes the intervention cohort, and $Z T_{t}, Z X_{t}$, and $Z X_{t} T_{t}$ are interaction terms. $\beta_{0}$ to $\beta_{3}$ relate to the control group as follows: $\beta_{0}$, intercept; $\beta_{1}$, pre-intervention trend; $\beta_{2}$, post-intervention step change; $\beta_{3}$, post-intervention trend. $\beta_{4}$ to $\beta_{7}$ represent differences between the control and intervention districts: $\beta_{4}$, difference in baseline intercepts; $\beta_{5}$, difference in preintervention trends; $\beta_{6}$, difference in post-intervention step changes; $\beta_{7}$, difference in post-intervention trend

${ }^{\mathrm{b}}$ The baseline rate denotes case notification rates per month

IRR based on log-linear GEE Poisson regression with correlation structures determined by the Cumby-Huizinga test and Quasi-Information Criteria

${ }^{\mathrm{d}}$ Wald test

volunteer districts. This finding was substantiated by the ITS analysis.

One explanation for the dichotomy in yield and additionality was the difference in screening activities. It is well documented that to find more cases a greater number of people need to be screened [40]. The higher number of screening encounters by the employees can be a proxy for time spent on outreach. The ability of full-time CHWs to achieve higher population coverage compared to volunteers has been noted in other settings [41]. Greater population coverage and community outreach have been cited as a catalyst for increased notifications [42].

Reports from the field also suggest that volunteers placed greater reliance on public health staff and neighborhood leaders to refer persons with suspected TB. This is intuitive given the lower remuneration and time commitment to ACF activities. Consequently, a greater proportion of individuals initiated on the TB care pathway by volunteers would have potentially been notified without this ACF intervention. This displacement of passive case finding has been documented among household contacts in Viet Nam [43].

However, as evinced by the PROPER CARE pilot [26], there is limited utility in an effective community engagement model that government stakeholders deem untenable for scale-up. As such, another positive finding of our study is that the volunteer human resource model still resulted in a significant increase in $\mathrm{TB}$ notifications for a lower cost. However, if resource-constrained programs choose to implement a volunteer-based human resource model, it will be necessary to consider other inherent risks besides lower additionality that may offset anticipated cost savings. Volunteers tend to require greater supervisory efforts to improve performance and ensure accurate reporting $[25,44]$. Past studies have also found volunteerism to be associated with lower value perception and job satisfaction [45]. Concordantly, the attrition in volunteer districts was higher than in salaried employee districts. 


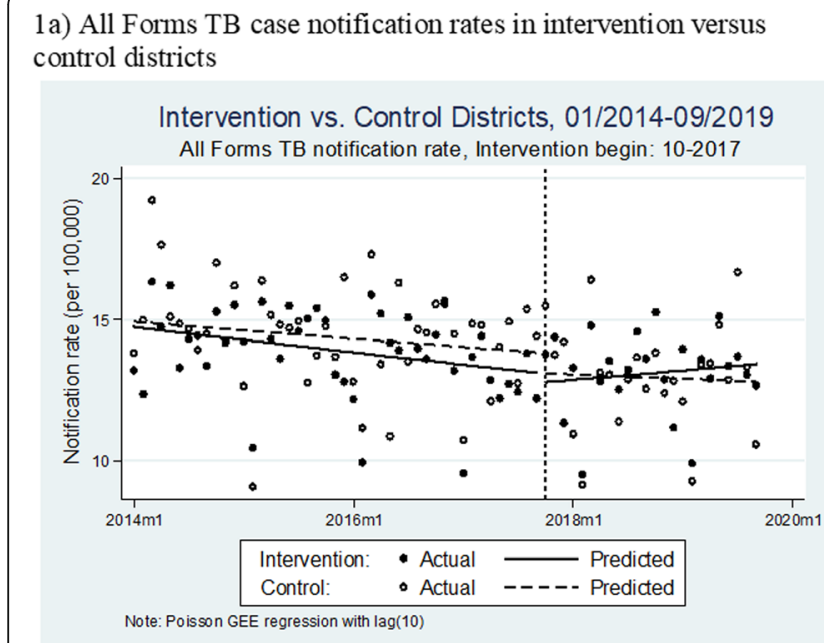

2a) Bacteriologically-confirmed TB case notification rates in intervention versus control districts

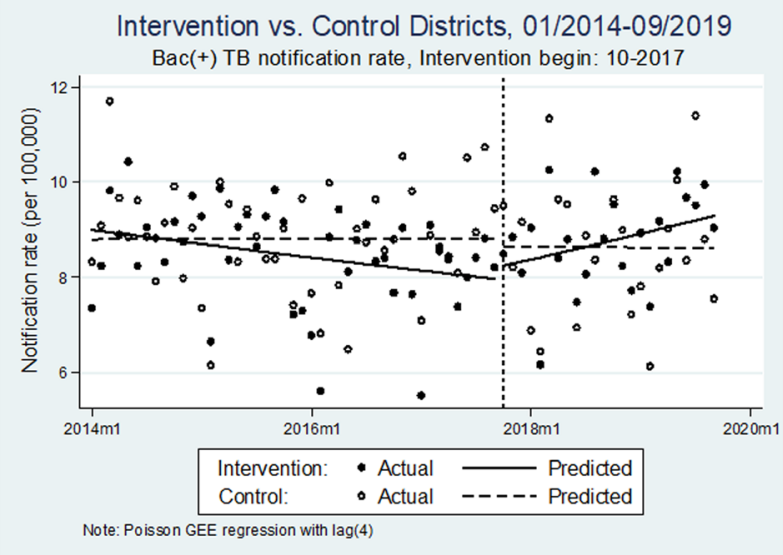

1b) All Forms TB case notification rates in employee ACF versus volunteer ACF districts

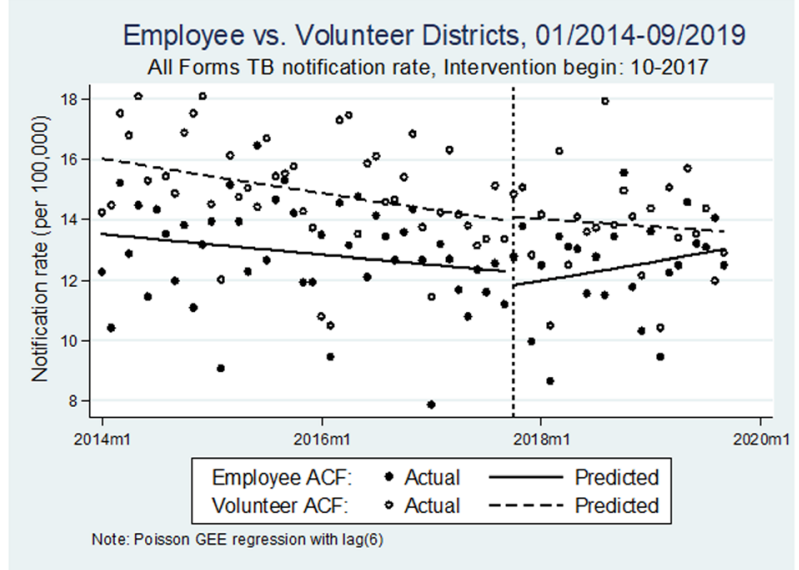

2b) Bacteriologically-confirmed TB case notification rates in employee ACF versus volunteer ACF districts

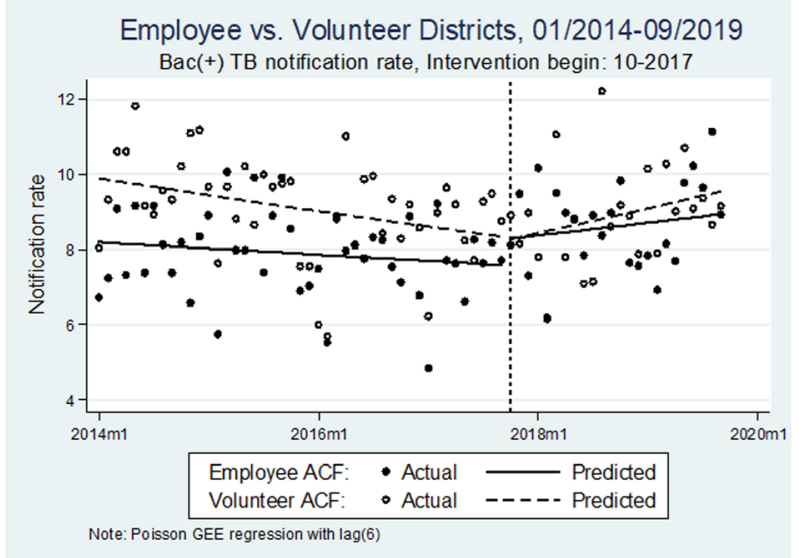

Fig. 3 Comparative ITS analysis model graphs of population-standardized monthly notification rates of 1) All Forms TB case notification rates; and 2) bacteriologically-confirmed TB case notification rates for a) intervention versus control districts; and b) employee ACF versus volunteer ACF

This was also the case among district supervisors. The attrition required continuous recruitment and capacity building, and possibly impaired quality of care. These downsides of volunteerism have been noted elsewhere $[46,47]$. A health economic analysis that incorporates the cost implications of the attrition and other operational challenges encountered in our study will be provided in a separate manuscript.

The Viet Nam NTP has already successfully replicated the volunteer model in cities with a lower TB burden and cost of living compared to HCMC, the economic center of Viet Nam [48]. In these cities the model generated comparable notification increases to the employee model in HCMC (manuscript in preparation). This suggests that the volunteer model could be appropriate in settings, where the workload and the opportunity cost of volunteering are lower. Appropriately powering incentives for the socioeconomic context and employing a blend of monetary and non-monetary incentives are further means to optimize volunteer models [49]. Lastly, future research may seek better ways to draw on the altruistic capital of volunteer CHWs to overcome operational challenges [50].

Our study had limitations. Conducting research in a programmatic setting exposed our study to supply chain interruptions. These interruptions affected the integration of study activities into routine program operations. However, this also reflects the reality of field scale-up of an intervention. While ITS analyses aim to increase validity and interpretability of the results by compensating for secular trends, we may have missed nuanced confounders due to the non-randomized study design. A strength of our study was the length and scale of our outreach as well as integration within the existing NTP 
Table 4 Comparative ITS analysis model parameters of population-standardized quarterly notification rates of All Forms and bacteriologically-confirmed TB cases for control versus non-IMPACT-TB districts ${ }^{\mathrm{a}, \mathrm{b}, \mathrm{c}}$

\begin{tabular}{|c|c|c|c|}
\hline & \multicolumn{3}{|c|}{ Control versus non-IMPACT-TB districts } \\
\hline & $\overline{\operatorname{IRR}^{d}}$ & $95 \% \mathrm{Cl}$ & $p$-value ${ }^{\mathbf{e}}$ \\
\hline \multicolumn{4}{|l|}{ All Forms TB } \\
\hline Baseline rate $\left(\beta_{0}\right)$ & 48.104 & {$[47.315,48.906]$} & $<0.001$ \\
\hline Pre-intervention trend, control $\left(\beta_{1}\right)$ & 0.995 & {$[0.994,0.997]$} & $<0.001$ \\
\hline Post-intervention step change, control $\left(\beta_{2}\right)$ & 0.795 & {$[0.763,0.829]$} & $<0.001$ \\
\hline Post-intervention trend, control $\left(\beta_{3}\right)$ & 1.006 & {$[0.997,1.015]$} & 0.168 \\
\hline Difference in baseline $\left(\beta_{4}\right)$ & 0.802 & {$[0.785,0.821]$} & $<0.001$ \\
\hline Difference in pre-intervention trends $\left(\beta_{5}\right)$ & 1.006 & {$[1.004,1.008]$} & $<0.001$ \\
\hline Difference in post-intervention step change $\left(\beta_{6}\right)$ & 1.012 & {$[0.957,1.071]$} & 0.667 \\
\hline Difference in post-intervention trends $\left(\beta_{7}\right)$ & 1.006 & {$[0.994,1.018]$} & 0.322 \\
\hline \multicolumn{4}{|l|}{ Bacteriologically-confirmed TB } \\
\hline Baseline rate $\left(\beta_{0}\right)$ & 27.461 & {$[26.677,28.268]$} & $<0.001$ \\
\hline Pre-intervention trend, control $\left(\beta_{1}\right)$ & 1.001 & {$[0.998,1.003]$} & 0.599 \\
\hline Post-intervention step change, control $\left(\beta_{2}\right)$ & 0.882 & {$[0.825,0.943]$} & $<0.001$ \\
\hline Post-intervention trend, control $\left(\beta_{3}\right)$ & 1.006 & {$[0.992,1.020]$} & 0.372 \\
\hline Difference in baseline $\left(\beta_{4}\right)$ & 0.810 & {$[0.779,0.843]$} & $<0.001$ \\
\hline Difference in pre-intervention trends $\left(\beta_{5}\right)$ & 1.003 & {$[1.000,1.006]$} & 0.053 \\
\hline Difference in post-intervention step change $\left(\beta_{6}\right)$ & 1.058 & {$[0.968,1.157]$} & 0.217 \\
\hline Difference in post-intervention trends $\left(\beta_{7}\right)$ & 0.994 & {$[0.976,1.013]$} & 0.553 \\
\hline
\end{tabular}

${ }^{a}$ The parameters were obtained for a segmented regression model with the following structure: $Y_{t}=\beta_{0}+\beta_{1} T_{t}+\beta_{2} X_{t}+\beta_{3} X_{t} T_{t}+\beta_{4} Z+\beta_{5} Z T_{t}+\beta_{6} Z X_{t}+\beta_{6} Z X_{t} T_{t}+\epsilon_{t}$. Here $\mathrm{Y}_{\mathrm{t}}$ is the outcome measure along time $\mathrm{t} ; \mathrm{T}_{\mathrm{t}}$ is the monthly time counter; $X_{t}$ indicates pre- and post-intervention periods, $Z$ denotes the intervention cohort, and $Z T_{t}, Z X_{t}$, and $Z X_{t} T_{t}$ are interaction terms. $\beta_{0}$ to $\beta_{3}$ relate to the control group as follows: $\beta_{0}$, intercept; $\beta_{1}$, pre-intervention trend; $\beta_{2}$, post-intervention step change; $\beta_{3}$, post-intervention trend. $\beta_{4}$ to $\beta_{7}$ represent differences between the control and intervention districts: $\beta_{4}$, difference in baseline intercepts; $\beta_{5}$, difference in preintervention trends; $\beta_{6}$, difference in post-intervention step changes; $\beta_{7}$, difference in post-intervention trend

${ }^{\mathrm{b}}$ The baseline rate denotes case notification rates per quarter as monthly notification rates were unavailable for non-study districts

'The non-IMPACT-TB districts included eight of the 12 remaining districts in HCMC. Four districts were excluded due to concurrent ACF interventions (Go Vap, 7 and 10) and large differences in population growth (Nha Be)

IIRR based on log-linear GEE Poisson regression with correlation structures as determined by the Cumby-Huizinga test and Quasi-Information Criteria eWald test

activities. As such, we believe in the transferability of our findings that effective engagement of CHWs can produce a positive notification impact and that full-time employment of CHWs can generate superior outcomes to other high ТB burden, resource-limited settings to inform local strategies to end TB.

\section{Conclusions}

Leveraging community networks to expand TB service coverage is both feasible and effective in diagnosing and treating additional persons with TB. Engaging full-time, salaried employee CHWs in TB ACF schemes can lead to greater impact, and this human resource model should be prioritized for scale up where resources permit. While further studies are needed to optimize this community engagement model, it can be a powerful and readily available tool for advancing the global End TB Strategy targets.

\section{Supplementary information}

Supplementary information accompanies this paper at https://doi.org/10. 1186/s12889-020-09042-4.

Additional file 1: Figure S1. Active TB case finding algorithm. Figure S2. Visualization of the comparative interrupted time-series analysis (intervention $=$ upper line, control = lower line). Table S1. Demographic and clinical characteristics of study participants.

\section{Abbreviations}

ACF: Active Case Finding; AFB: Acid-fast Bacilli; CHW: Community Health Worker; Cl: Confidence Interval; CXR: Chest X-ray; DTU: District TB Unit; EP: Extra-pulmonary; GEE: Generalized Estimating Equation; HCMC: Ho Chi Minh City; IRR: Incidence Rate Ratio; ITS: Interrupted Time Series; NNS: Number Needed to Screen; NTP: National TB Control Program; PBI: Performance-based Incentive; PNTH: Pham Ngoc Thach Provincial TB Hospital; TB: Tuberculosis; WHO: World Health Organization

\section{Acknowledgements}

We express our sincere gratitude to the Viet Nam National Tuberculosis Programme, Pham Ngoc Thach Provincial TB Hospital and the DTUs in Districts 1, 2, 3, 4, 6, 8, 12, Tan Binh, Hoc Mon, Binh Chanh, Binh Thanh and Thu Duc for their participation in the study. We thank the field staff of the 
Ho Chi Minh City Public Health Association. We are deeply grateful for the hundreds of CHWs, who tirelessly worked to support the study, their communities and their patients.

\section{Authors' contributions}

Conceptualization: LNQV, TNV, GTL, GCD, WT, LHN, NVN, BS, KL, MC. Data curation: LNQV, RJF, AJC, TNV, JL. Formal analysis: LNQV, AJC, JL. Funding acquisition: LNQV, BS, KL, MC. Investigation: LNQV, RJF, AJC, WT, MC. Methodology: LNQV, RJF, GCD, HBN, BS, KL, MC. Project administration: LNQV, RJF, AJC, TNV, GCD, WT, MC. Supervision: LNQV, GTL, HMD, LHN, HBN, NVN, BS, KL, MC. Final approval: all authors have read and approved the manuscript

\section{Funding}

The IMPACT-TB study and LNQV, AJC, RJF, TNV, GTL, JL, BS, KL and MC were supported by the European Commission's Horizon 2020 programme under grant agreement number 733174. We received additional support from the Stop TB Partnership's TB REACH initiative with funding from the Government of Canada. These funding bodies had no role in the design of the study, in collection, analysis, and interpretation of data, or in writing the manuscript.

\section{Availability of data and materials}

The data that support the findings of this study are available from the Viet Nam National TB Control Program and Pham Ngoc Thach Provincial TB Hospital, but restrictions apply to the availability of these data. Data are can be made available from the authors upon reasonable request and with permission of the Viet Nam National TB Control Program and Pham Ngoc Thach Provincial TB Hospital.

\section{Ethics approval and consent to participate}

Approvals were granted by the PNTH Institutional Review Board and the Liverpool School of Tropical Medicine Research Ethics Committee. Study implementation was approved by the HCMC People's Committee. The Pham Ngoc Thach Provincial TB Hospital approved use of the data. We obtained written informed consent from all participants and anonymized all patient data prior to analysis.

\section{Consent for publication}

Not applicable.

\section{Competing interests}

The authors declare that they have no competing interests with regard to this work.

\section{Author details}

${ }^{1}$ Friends for International TB Relief, 68B Nguyen Van Troi, 8, Phu Nhuan, Ho Chi Minh City, Viet Nam. ${ }^{2}$ Interactive Research and Development, Ho Chi Minh City, Viet Nam. ${ }^{3} \mathrm{Ho}$ Chi Minh City Public Health Association, Ho Chi Minh City, Viet Nam. ${ }^{4}$ Pham Ngoc Thach Hospital, Ho Chi Minh City, Viet Nam. ${ }^{5}$ National Lung Hospital, Ha Noi, Viet Nam. ${ }^{6}$ KNCV Tuberculosefonds, The Hague, The Netherlands. 'Liverpool School of Tropical Medicine, Department of Clinical Sciences, Liverpool, UK. ${ }^{8}$ Karolinska Institutet, Department of Global Public Health, Stockholm, Sweden. ${ }^{9}$ Birat Nepal Medical Trust, Lazimpat, Kathmandu, Nepal.

Received: 19 February 2020 Accepted: 3 June 2020

\section{Published online: 15 June 2020}

\section{References}

1. Global Tuberculosis Report 2018. Geneva: World Health Organization; 2018.

2. Ortblad KF, Lozano R, Murray CJ. An alternative estimation of tuberculosis incidence from 1980 to 2010: methods from the global burden of disease 2010. Lancet. 2013;381:S104.

3. Yuen CM, Amanullah F, Dharmadhikari A, Nardell EA, Seddon JA, Vasilyeva I, et al. Turning off the tap: stopping tuberculosis transmission through active case-finding and prompt effective treatment. Lancet. 2015;386(10010):2334-43.

4. Kunii O, Yassin MA, Wandwalo E. Investing to end epidemics : the role of the Global Fund to control TB by 2030. Trans R Soc Trop Med Hyg. 2016; 110:153-4.
5. Golub JE, Mohan Cl, Comstock GW, Chaisson RE. Active case finding of tuberculosis: historical perspective and future prospects. Int J Tuberc Lung Dis. 2005;9(11):1183-203.

6. Hinderaker SG, Rusen ID, Chiang CY, Yan L, Heldal E, Enarson DA. The FIDELIS initiative: innovative strategies for increased case finding. Int J Tuberc Lung Dis. 2011;15(1):71-6.

7. Creswell J, Sahu S, Blok L, Bakker MI, Stevens R, Ditiu L. A multi-site evaluation of innovative approaches to increase tuberculosis case notification: Summary results. PLoS One. 2014;9(4):e94465.

8. Do TT, Kumar AM, Ramaswamy G, Htun T, Le VH, Vo LNQ, et al. An innovative public - private mix model for improving tuberculosis Care in Vietnam : how well are we doing ? Trop Med Infect Dis. 2020;5(26):1-14.

9. Vo LNQ, Codlin AJ, Forse RJ, Nguyen HT, Vu TN, Van Truong V, et al. Tuberculosis among economic migrants: a cross-sectional study of the risk of poor treatment outcomes and impact of a treatment adherence intervention among temporary residents in an urban district in Ho Chi Minh City, Viet Nam. BMC Infect Dis. 2020;20(1):134 Available from: https://bmcinfectdis.biomedcentral.com/articles/10.11 86/s12879-020-4865-7.

10. Creswell J, Codlin AJ, Andre E, Micek MA, Bedru A, Carter EJ, et al. Results from early programmatic implementation of Xpert MTB/RIF testing in nine countries. BMC Infect Dis. 2014;14(2). https://doi.org/10.1186/1471-2334-142.

11. Fatima R, Qadeer E, Enarson DA, Creswell J, Stevens R, Hinderaker SG, et al. Success of active tuberculosis case detection among high-risk groups in urban slums in Pakistan. Int J Tuberc Lung Dis. 2014;18(9):1099-104.

12. Wingfield T, Verguet S. Active case finding in tuberculosis-affected households: time to scale up. Lancet Glob Health. 2019;7(3):e296-8.

13. World Health Organization. Declaration of Alma-Ata 1978. In: International Conference on Primary Health Care, Alma-Ata, USSR, 6-12 September 1978; 1978. p. 3.

14. Jareg P, Kaseje DCO. Growth of civil society in developing countries: implications for health. Lancet. 1998;351(9105):819-22.

15. Community involvement in tuberculosis care and prevention : towards partnerships for health : guiding principles and recommendations based on aWHO review. Geneva: World Health Organization; 2008.

16. Engage-TB: integrating community-based tuberculosis activities into the work of nongovernmental and other civil society organizations: operational guidance. Geneva: World Health Organization; 2012.

17. Olaniran A, Smith $H$, Unkels R, Bar-Zeev S, van den Broek N. Who is a community health worker? - A systematic review of definitions. Glob Health Action. 2017;10(1):1272223. https://doi.org/10.1080/16549716.2017.1272223.

18. WHO guideline on health policy and system support to optimize community health worker programmes. Geneva: World Health Organization; 2018.

19. Smith S, Deveridge A, Berman J, Negin J, Mwambene N, Chingaipe E, et al. Task-shifting and prioritization: a situational analysis examining the role and experiences of community health workers in Malawi. Hum Resour Health. 2014;12(24):1-13.

20. Yassin MA, Datiko DG, Tulloch O, Markos P, Aschalew M, Shargie EB, et al. Innovative community-based approaches doubled tuberculosis case notification and improve treatment outcome in southern Ethiopia. PLoS One. 2013;8(5):1-8.

21. Getahun H, Raviglione M. Transforming the global tuberculosis response through effective engagement of civil society organizations: the role of the World Health Organization. Bull World Health Organ. 2011;89(8):616-8.

22. Stop TB Field Guide 3: Finding Missing People with TB in communities. Geneva: Stop TB Partnership; 2018.

23. Agarwal S, Kirk K, Sripad P, Bellows B, Abuya T, Warren C. Setting the global research agenda for community health systems : literature and consultative review. Hum Resour Health. 2019;17(22):1-8.

24. Cometto G, Ford N, Pfaffman-Zambruni J, Akl EA, Lehmann U, McPake B, et al. Health policy and system support to optimise community health worker programmes: an abridged WHO guideline. Lancet Glob Health. 2018; 6(12):e1397-404. https://doi.org/10.1016/S2214-109X(18)30482-0.

25. Bhutta ZA, Lassi ZS, Pariyo G, Huicho L. Global Experience of Community Health Workers for Delivery of Health Related Millennium Development Goals. Karachi: The Aga Khan University; 2010.

26. Nguyen TH, Vo Nguyen Quang L, Le TG VNT, Nguyen HD. Results of the community - based intervention for the prevention and control of TB in Go Vap district, Ho Chi Minh city , 2014 [vietnamese]. Viet Nam J Public Health. 2015;38:6-12 
27. Vo LNQ, Vu TN, Nguyen HT, Truong T, Khuu CM, Pham PQ, et al. Optimizing community screening for tuberculosis : spatial analysis of localized case finding from door-to-door screening for TB in an urban district of $\mathrm{Ho}_{\mathrm{C}} \mathrm{Chi}$ Minh City, Viet Nam. PLoS One. 2018;13(12):e0209290.

28. UN-Habitat. Slum Almanac 2015/2016: Tracking improvement in the lives of slum dwellers. Participatory Slum Upgrading Programme. 2016.

29. Blok L, Creswell J, Stevens R, Brouwer M, Ramis O, Weil O, et al. A pragmatic approach to measuring monitoring and evaluating interventions for improved tuberculosis case detection. Int Health. 2014;6(3):181-8.

30. MacPherson P, Houben RM, Glynn JR, Corbett EL, Kranzer K. Pre-treatment loss to follow-up in tuberculosis patients in low- and lower-middle-income countries and high-burden countries: a systematic review and meta-analysis. Bull World Health Organ. 2014;92(2):126-38.

31. Datiko DG, Yassin MA, Theobald SJ, Blok L, Suvanand S, Creswell J, et al. Health extension workers improve tuberculosis case finding and treatment outcome in Ethiopia: a large-scale implementation study. BMJ Glob Health. 2017;2(4):1-8

32. John S, Gidado M, Dahiru T, Fanning A, Codlin AJ, Creswell J. Tuberculosis among nomads in Adamawa, Nigeria: outcomes from two years of active case finding. Int J Tuberc Lung Dis. 2015;19(4):463-8.

33. Becerra MC, Pachao-Torreblanca IF, Bayona J, Celi R, Shin SS, Kim JY, et al. Expanding tuberculosis case detection by screening household contacts. Public Health Rep. 2005;120(June):271-7.

34. Volkmann T, Okelloh D, Agaya J, Cain K, Ooko B, Malika T, et al. Pilot implementation of a contact tracing intervention for tuberculosis case detection in Kisumu County, Kenya. Public Health Action. 2016;6(4):217-9.

35. Lorent N, Choun K, Thai S, Kim T, Huy S, Pe R, et al. Community-based active tuberculosis case finding in poor urban settlements of Phnom Penh, Cambodia: a feasible and effective strategy. PLoS One. 2014;9(3):1-12.

36. Corbett EL, Bandason T, Duong T, Dauya E, Makamure B, Churchyard GJ, et al. Comparison of two active case-finding strategies for communitybased diagnosis of symptomatic smear-positive tuberculosis and control of infectious tuberculosis in Harare, Zimbabwe (DETECTB): a clusterrandomised trial. Lancet. 2010;376(9748):1244-53.

37. Sinha P, Shenoi SV, Friedland GH. Opportunities for community health workers to contribute to global efforts to end tuberculosis. Glob Public Health. 2019;0(0):1-11. https://doi.org/10.1080/17441692.2019.1663361.

38. Shelley KD, Frumence G, Mpembeni R, George AS, Stuart EA, Killewo J, et al. Can volunteer community health workers manage multiple roles? An interrupted time-series analysis of combined HIV and maternal and child health promotion in Iringa, Tanzania. Health Policy Plan. 2018;33(10):1096-106.

39. Lorent N, Choun K, Malhotra S, Koeut P, Thai S, Khun KE, et al. Challenges from tuberculosis diagnosis to care in community-based active case finding among the urban poor in Cambodia: a mixed-methods study. PLoS One. 2015;10(7):1-15

40. Lönnroth K, Corbett E, Golub J, Godfrey-Faussett P, Uplekar M, Weil D, et al. Systematic screening for active tuberculosis: rationale, definitions and key considerations. Int J Tuberc Lung Dis. 2013;17(3):289-98.

41. Singh D, Negin J, Otim M, Orach CG, Cumming R. The effect of payment and incentives on motivation and focus of community health workers: Five case studies from low- and middle-income countries. Hum Resour Health. 2015;13(1). https://doi.org/10.1186/s12960-015-0051-1.

42. Blok L, Sahu S, Creswell J, Alba S, Stevens R, Bakker MI. Comparative metaanalysis of tuberculosis contact investigation interventions in eleven high burden countries. PLoS One. 2015;10(3):1-18

43. Fox GJ, Nhung NV, Sy DN, Hoa NLP, Anh LTN, Anh NT, et al. HouseholdContact Investigation for Detection of Tuberculosis in Vietnam Supplementary Appendix. N Engl J Med. 2018;378(3):221-9 Available from: http://www.nejm.org/doi/10.1056/NEJMoa1700209.

44. Bhattacharyya K, Winch P, LeBan K, Tien M. Community Health Worker Incentives and Disincentives: How They Affect Motivation, Retention, and Sustainability. In: Published by the Basic Support for Institutionalizing Child Survival Project (BASICS II) for the United States Agency for International Development. Arlington, Virginia: Partnership for Child Health Care, Inc., 2001.

45. Sarin E, Lunsford SS, Sooden A, Rai S, Livesley N. The mixed nature of incentives for community health workers: lessons from a qualitative study in two districts in India. Front Public Health. 2016;4(March):1-7.

46. Adejumo AO, Azuogu B, Okorie O, Lawal OM, Onazi OJ, Gidado M, et al. Community referral for presumptive TB in Nigeria : a comparison of four models of active case finding. BMC Public Health. 2016:1-9. https://doi.org/ 10.1186/s12889-016-2769-7.
47. Scott K, Beckham SW, Gross M, Pariyo G, Rao KD, Cometto G, et al. What do we know about community-based health worker programs? A systematic review of existing reviews on community health workers. Hum Resour Health. 2018;16(1):1-17.

48. United Nations Development Programme. Growth that works for all : Viet Nam human development report 2015 on inclusive growth. Ha Noi; 2016. Available from: http://hdr.undp.org/sites/default/files/nhdr_2015_e.pdf.

49. Ballard $M$, Montgomery P. Systematic review of interventions for improving the performance of community health workers in low-income and middleincome countries. BMJ Open. 2017;7(10):e014216. https://doi.org/10.1136/ bmjopen-2016-014216.

50. Ashraf N, Bandiera O. Altruistic capital. Am Econ Rev. 2017;107(5):70-5

\section{Publisher's Note}

Springer Nature remains neutral with regard to jurisdictional claims in published maps and institutional affiliations.
Ready to submit your research? Choose BMC and benefit from:

- fast, convenient online submission

- thorough peer review by experienced researchers in your field

- rapid publication on acceptance

- support for research data, including large and complex data types

- gold Open Access which fosters wider collaboration and increased citations

- maximum visibility for your research: over $100 \mathrm{M}$ website views per year

At BMC, research is always in progress.

Learn more biomedcentral.com/submissions 